\title{
Heat Capacities and Derived Thermodynamic Functions of 1-Hexanol, 1-Heptanol, 1-Octanol, and 1-Decanol between $5 \mathrm{~K}$ and $390 \mathrm{~K}$
}

\author{
J. Cees van Miltenburg* \\ Chemical Thermodynamics Group, Debye Institute, Utrecht University, Padualaan 8, \\ 3584-CH Utrecht, The Netherlands
}

Hana Gabrielová and Květoslav R ůžička

Department of Physical Chemistry, Institute of Chemical Technology, 16628 Prague 6, Czech Republic

\begin{abstract}
Molar heat capacities of the linear alcohols 1-hexanol $\left(\mathrm{C}_{6} \mathrm{H}_{14} \mathrm{O}\right)$, 1-heptanol $\left(\mathrm{C}_{7} \mathrm{H}_{16} \mathrm{O}\right)$, 1-octanol $\left(\mathrm{C}_{8} \mathrm{H}_{18} \mathrm{O}\right)$, and 1-decanol $\left(\mathrm{C}_{10} \mathrm{H}_{22} \mathrm{O}\right)$ were measured from $5 \mathrm{~K}$ to $390 \mathrm{~K}$. The derived thermodynamic functions $\mathrm{S}_{\mathrm{abs}, \mathrm{m}}(\mathrm{T})$ and $\mathrm{H}_{\mathrm{m}}(\mathrm{T})-\mathrm{H}_{\mathrm{m}}(0)$ were calculated. Including earlier published data, a correlation for the heat capacity of the liquid 1-alcohols with the carbon number $\mathrm{n}$ in the chain ranging between 6 and 22 was fitted. The molar heat capacities of the liquid alcohols can be described by $\left.C_{p, 1}(n, T) /\right] \cdot K^{-1} \cdot \mathrm{mol}^{-1}=$ $-3163.5+21.0156 n+0.04223 n T+9.89055 T+322705.7 / T-0.0093225 T^{2}$, with the mean absolute percentage deviation being $0.22 \%$. The correlation for the absolute entropy is $\mathrm{S}^{\circ}(360 \mathrm{~K}, \mathrm{n})=(111.86+$ $38.613 \mathrm{n}) \mathrm{J} \cdot \mathrm{K}^{-1} \cdot \mathrm{mol}^{-1}$.
\end{abstract}

\section{Introduction}

This work is concerned with heat capacity measurements on lower 1-alcohols from about $5 \mathrm{~K}$ up to room temperature and higher (to $390 \mathrm{~K}$ ). 1-Hexanol was measured from $5 \mathrm{~K}$ to $400 \mathrm{~K}$, 1-heptanol was measured from $5 \mathrm{~K}$ to $370 \mathrm{~K}$, 1-octanol was measured from $5 \mathrm{~K}$ up to $380 \mathrm{~K}$, and 1-decanol was measured from $5 \mathrm{~K}$ to $390 \mathrm{~K}$. In earlier publications heat capacity data and derived thermodynamic properties of the normal 1-alcohols with carbon numbers $12,13,15,17,18,19,20$, and 22 were presented. ${ }^{1,2}$ We are especially interested in the heat capacity of the liquid 1-al cohols, and in order to get a consistent set of data, the measurements were extended to the alcohols presented in this article with the number of carbon atoms in the chain of $6,7,8$, and 10. A survey of the literature sources on saturated liquid heat capacities of 1 -alcohols is given in the monograph by Zábranský et al. ${ }^{3}$ We compare our results to those data measured by adiabatic calorimetry or microcalorimetry, and we have included in the figures the data from the NIST databank ${ }^{4}$ given at $298.15 \mathrm{~K}$, which were measured by different methods, but mostly by DSC. Another object of this study is to extend the available absolute entropy data of the 1-alcohols and to find the correlation of these values with the number of carbon atoms in the chain.

\section{Experimental Section}

1-Heptanol was bought from Aldrich, and 1-hexanol, 1-octanol, and 1-decanol were bought from Merck. All the compounds were purified by fractional distillation at a reduced pressure of approximately $70 \mathrm{~Pa}$ in a $110 \mathrm{~cm}$ long packed column with a heated outer housing. After distillation the compounds were stored over molecular sieves (Merck) with a pore diameter of $0.4 \mathrm{~nm}$, for a minimum of 4 days.
Table 1. Purity of the Compounds As Given by the Supplier and Measured by Gas Chromatography, Fischer Titration, and Adiabatic Calorimetry

\begin{tabular}{|c|c|c|c|c|c|}
\hline & $\begin{array}{l}\text { stated } \\
\text { purity } \\
\end{array}$ & $\begin{array}{c}\text { meas purity } \\
\text { without water } \\
\end{array}$ & $\begin{array}{c}\text { water } \\
\text { content } \\
\end{array}$ & $\begin{array}{c}\text { tot } \\
\text { purity } \\
\end{array}$ & $\begin{array}{c}\text { calorim } \\
\text { value } \\
\end{array}$ \\
\hline compd & $\overline{\mathrm{mol} \%}$ & $\mathrm{~mol} \%$ & $\overline{\text { mass } \%}$ & $\overline{\mathrm{mol} \%}$ & $\overline{\mathrm{mol} \%}$ \\
\hline 1-hexanol & 98 & 99.98 & 0.03 & 99.81 & 99.80 \\
\hline 1-heptanol & 98 & 99.93 & 0.02 & 99.80 & 99.78 \\
\hline 1-octanol & $>99$ & 99.97 & 0.02 & 99.83 & 99.82 \\
\hline 1-decanol & $>99$ & 99.88 & 0.007 & 99.82 & 99.78 \\
\hline
\end{tabular}

The purity of the compounds was determined using a Hewlett-Packard 6890 series gas chromatograph, using a flame ionization detector. The water content was determined by a Fischer titration. The final purity (excluding water content) and water content are given in Table 1.

Care was taken to avoid contact with the air. The calorimeter vessel was filled in a glovebox under a dry nitrogen atmosphere. 1-Hexanol and 1-octanol were measured in CALV (laboratory design indication).5,6 Below 30 $\mathrm{K}$, the reproducibility of this calorimeter is about $1 \%$, between $30 \mathrm{~K}$ and $100 \mathrm{~K}$, it is 0.05 to $0.1 \%$, and above 100 $\mathrm{K}$, it is $0.03 \%$. 1-Heptanol and 1 -decanol were measured in CALVII (laboratory design indication). This cal orimeter is identical to CALV, but uses a platinum $100 \Omega$ thermometer instead of a Rh/Fe resistance thermometer. Oxford Instruments calibrated the thermometers to an accuracy of $0.001 \mathrm{~K}$ using the ITS-907 temperature scale. The accuracy of the heat capacity measurements was checked for both calorimeters by measuring n-heptane and synthetic sapphire. No deviations from the recommended values larger than $0.2 \%$ were found. Measurements were made in the intermittent mode, using stabilization periods of about $600 \mathrm{~s}$ and heat input periods of about $500 \mathrm{~s}$. Below $30 \mathrm{~K}$ shorter time periods were used. I $\mathrm{n}$ the melting region longer stabilization periods, up to 1200 s, were used. For each compound a slow controlled cooling curve with a 
Table 2. Experimental Molar Heat Capacities ${ }^{a}$ of 1-Hexanol

\begin{tabular}{|c|c|c|c|c|c|c|c|}
\hline T & $C_{p}$ & $\mathrm{~T}$ & $C_{p}$ & $\mathrm{~T}$ & $C_{p}$ & $\mathrm{~T}$ & $C_{p}$ \\
\hline 4.73 & 0.23 & 39 & 6 & 11 & 241.18 & 3.95 & 0 \\
\hline 4.7 & 0.26 & & & 224 & 519 & & \\
\hline 5.03 & 0.22 & 9 & & 225.81 & 1592 & & \\
\hline 5.25 & 0.28 & & & & & & \\
\hline 60 & & & & & 7148 & & \\
\hline 6.23 & & 77 & 9 & 226 & 12030 & & \\
\hline 6.6 & 0 & 79.82 & 69.05 & & & & \\
\hline 7.29 & 0 & & & & & & \\
\hline 7.59 & 0.66 & & & 226.55 & 39292 & & 265. \\
\hline 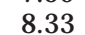 & 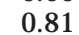 & 8 & & 226 & & & \\
\hline & & & & & 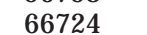 & & \\
\hline 9.1 & 1.13 & 1 & 79.10 & 226 & 86529 & & \\
\hline 9.4 & 1.7 & 96.73 & & 226.61 & & & 72.9 \\
\hline n & & 5 & & & & & 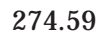 \\
\hline & 1. & 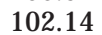 & & & & & \\
\hline & & & & & & & \\
\hline & 2.15 & 11 & & & & & \\
\hline & & & & & & & \\
\hline & & & & & & & \\
\hline & & & & & & & \\
\hline & & & & & & & \\
\hline & & & & & & & \\
\hline & & & & & & & \\
\hline & & & & & & & \\
\hline & & 9 & & & & & \\
\hline & & 35.80 & & & & & \\
\hline & & & & & & & \\
\hline & & & & & & & \\
\hline & & & & & & & \\
\hline & & & & & & & \\
\hline & & & & & & & \\
\hline & & & & & & & \\
\hline & & & & & & & \\
\hline & & & & & & & \\
\hline & & & & & & & \\
\hline & & & & & & & \\
\hline & & & & & & & \\
\hline & & & & & & & \\
\hline & & & & & & & \\
\hline & & & & & & & \\
\hline & & & & & & & \\
\hline & & & & & & & \\
\hline & & & & & & & \\
\hline & & & & & & & \\
\hline & & & & & & & \\
\hline & & & & & & & \\
\hline & & & & & & & \\
\hline & & & & & & & \\
\hline & & & & & & & \\
\hline & & & & & & & \\
\hline & & & & & & & \\
\hline & & 2 & & & & 394.53 & \\
\hline & & & & & & & \\
\hline & & & & & & & \\
\hline & & & & & & & \\
\hline
\end{tabular}

a $\mathrm{ln} \mathrm{J} \cdot \mathrm{K}^{-1} \cdot \mathrm{mol}^{-1}$ at temperatures in $\mathrm{K}$.

cooling rate of about $4 \mathrm{~K} \cdot \mathrm{h}^{-1}$ was made before starting the heat capacity measurements in order to check for metastable solid phases.

After completion of the measurement, the data were combined in one file. For all compounds several runs were made and each temperature range was measured at least twice. With these four compounds no influence of the thermal history was found, and as the reproducibility of the calorimeter is better than the above stated accuracy, we give in the tables of experimental data those data which form a continuous set from the lowest to the highest measuring temperature. The heat capacity data in the melting region reach very high values, which are not suited for calculating the enthal py of fusion. This calculation must be done with the enthalpy curve. We have included
Table 3. Experimental Enthalpy Increments for 1-Hexanol around the Melting Point

\begin{tabular}{|c|c|c|c|c|c|}
\hline $\mathrm{T}$ & $\mathrm{H}-\mathrm{H}_{\text {start }}$ & $\mathrm{T}$ & $\mathrm{H}-\mathrm{H}_{\text {start }}$ & $T$ & $\mathrm{H}-\mathrm{H}_{\text {start }}$ \\
\hline K & $\mathrm{J} \cdot \mathrm{mol}^{-1}$ & K & $\mathrm{J} \cdot \mathrm{mol}^{-1}$ & $K$ & $\mathrm{~J} \cdot \mathrm{mol}^{-1}$ \\
\hline \multicolumn{2}{|c|}{$\operatorname{Exp} 1$} & 226.63 & 25175 & 226.49 & 19038 \\
\hline 218.71 & 11620 & 226.63 & 26037 & 226.52 & 19896 \\
\hline 221.44 & 12095 & 226.64 & 26899 & 226.55 & 20755 \\
\hline 223.80 & 12630 & 226.65 & 27759 & 226.57 & 21615 \\
\hline 225.34 & 13282 & 226.72 & 28612 & 226.58 & 22476 \\
\hline 226.01 & 14051 & 227.49 & 29368 & 226.60 & 23338 \\
\hline 226.27 & 14878 & 229.48 & 29956 & 226.61 & 24200 \\
\hline 226.40 & 15723 & 232.03 & 30466 & 226.61 & 25062 \\
\hline 226.47 & 16574 & \multicolumn{2}{|c|}{$\operatorname{Exp} 2$} & 226.62 & 25924 \\
\hline 226.52 & 17430 & 214.98 & 12896 & 226.62 & 26787 \\
\hline 226.55 & 18288 & 217.85 & 13339 & 226.62 & 27650 \\
\hline 226.57 & 19148 & 220.62 & 13806 & 226.63 & 28513 \\
\hline 226.59 & 20008 & 223.11 & 14323 & 226.63 & 29375 \\
\hline 226.60 & 20868 & 224.91 & 14939 & 226.65 & 30236 \\
\hline 226.61 & 21730 & 225.81 & 15678 & 227.08 & 31040 \\
\hline 226.61 & 22591 & 226.17 & 16492 & 228.77 & 31670 \\
\hline 226.62 & 23452 & 226.33 & 17332 & 231.33 & 32179 \\
\hline & 21314 & 43 & 18183 & & \\
\hline
\end{tabular}

Table 4. Equilibrium Temperatures in the Melt and the Reciprocal of the Melted Fraction of 1-Hexanol

\begin{tabular}{|c|c|c|c|c|c|c|c|}
\hline \multicolumn{4}{|c|}{ experiment 1} & \multicolumn{4}{|c|}{ experiment 2} \\
\hline $\mathrm{T} / \mathrm{K}$ & $\mathrm{F}^{-1}$ & $\mathrm{~T} / \mathrm{K}$ & $\mathrm{F}$ & $\mathrm{T} / \mathrm{K}$ & $\mathrm{F}^{-1}$ & $\mathrm{~T} / \mathrm{K}$ & $\mathrm{F}^{-1}$ \\
\hline 6.012 & 11.293 & 6.614 & 1.6 & 26.16 & 8.1 & 26.61 & 1.58 \\
\hline & & & & & & & \\
\hline & 5.4 & 226 & 1.4 & & & & 1.3 \\
\hline & & & & & & & \\
\hline & & & & & & & \\
\hline & 2.9 & & 1.1 & & 2. & & 1.1 \\
\hline & 25 & & 1.1 & & 2.354 & & 1.06 \\
\hline & 2.2 & & 1.0 & & & & 1.01 \\
\hline & 2.0 & & & & & & \\
\hline & 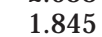 & 80 & 1. & & 1.727 & 25 & 10 \\
\hline
\end{tabular}

Table 5. Melting Experiments of 1-Hexanola

\begin{tabular}{|c|c|c|}
\hline & triple point & $\Delta H_{\text {fusion }}$ \\
\hline experiment & K & $\mathrm{J} \cdot \mathrm{mol}^{-1}$ \\
\hline $\begin{array}{l}1 \\
2 \\
\text { mean }\end{array}$ & $\begin{array}{l}226.69 \\
226.70 \\
226.70+0.02\end{array}$ & $\begin{array}{l}16723 \\
16735 \\
16729+35\end{array}$ \\
\hline
\end{tabular}

a The following linear fits of the heat capacity were used to calculate the enthalpy of fusion: $C_{p}($ solid $)=\{36.50+0.4890 T\}$ $\mathrm{J} \cdot \mathrm{K}^{-1} \cdot \mathrm{mol}^{-1}$ and $\mathrm{C}_{\mathrm{p}}($ liquid $)=\{103.88+0.4154 \mathrm{~T}\} \mathrm{J} \cdot \mathrm{K}^{-1} \cdot \mathrm{mol}^{-1}$.

separate tables for the melting experiments in which the enthalpy data are also given. For the calculation of the purity a sigmoid baseline was constructed using as starting values for the heat capacity of the solid and the liquid linear fits. These fits are given in the tables which contain the measured enthal pies of fusion. The observed equilibrium temperatures in the melt are probably correct to a relative precision of 0.001 or $0.002 \mathrm{~K}$, as sufficient time was taken to reach equilibrium to within this limit. Those data are also given together with the calculated reciprocal values of the melted fraction. The purity was calculated using the van't Hoff relation

$$
\left(T_{\text {triple }}-T_{\text {eq }}\right)=\frac{R T_{\text {triple }}^{2}}{\Delta H_{\text {fus }}} \frac{X}{F}
$$

in which $T_{\text {triple }}$ is the triple point temperature, $T_{\text {eq }}$ is the experimental equilibrium temperature in the melt at the melted fraction $\mathrm{F}, \mathrm{x}$ is the impurity in moles, and $\Delta \mathrm{H}_{\text {fus }}$ is the calculated enthal py of fusion.

Between $4 \mathrm{~K}$ and $30 \mathrm{~K}$ the measurements were repeated three times and fitted to the low-temperature limit of the 
Table 6. Thermodynamic Properties at Selected Temperatures for 1-Hexanol Molar Mass $=102.18 \mathrm{~g} \cdot \mathrm{mol}^{-1}$

\begin{tabular}{|c|c|c|c|}
\hline $\begin{array}{l}\mathrm{T} \\
\mathrm{K}\end{array}$ & $\frac{\mathrm{C}_{\mathrm{p}, \mathrm{m}}^{\circ}}{\cdot \mathrm{K}^{-1} \cdot \mathrm{mol}^{-1}}$ & $\frac{\mathrm{S}_{\mathrm{m}}^{\circ}}{\cdot \mathrm{K}^{-1} \cdot \mathrm{mol}^{-1}}$ & $\frac{\Delta \mathrm{H}_{\mathrm{m}}^{\circ}}{\cdot \cdot \mathrm{mol}^{-1}}$ \\
\hline 10 & 147 & 49 & 37 \\
\hline 20 & $\begin{array}{l}1.41 \\
8.47\end{array}$ & $\begin{array}{l}0.49 \\
3.33\end{array}$ & $\begin{array}{r}3.1 \\
48.6\end{array}$ \\
\hline 30 & 19.07 & 8.73 & 185 \\
\hline 40 & 30.56 & 15.83 & 435 \\
\hline 50 & 41.99 & 23.89 & 798 \\
\hline 60 & 52.09 & 32.47 & 1270 \\
\hline 70 & 61.11 & 41.18 & 1837 \\
\hline 80 & 69.18 & 49.88 & 2489 \\
\hline 90 & 76.46 & 58.46 & 3218 \\
\hline 100 & 83.02 & 66.85 & 4015 \\
\hline 110 & 89.30 & 75.07 & 4878 \\
\hline 120 & 94.61 & 83.08 & 5798 \\
\hline 130 & 100.4 & 90.87 & 6773 \\
\hline 140 & 105.1 & 98.48 & 7800 \\
\hline 150 & 110.0 & 105.9 & 8876 \\
\hline 160 & 114.8 & 113.2 & 10000 \\
\hline 170 & 119.5 & 120.3 & 11171 \\
\hline 180 & 124.4 & 127.2 & 12390 \\
\hline 190 & 129.6 & 134.1 & 13659 \\
\hline 200 & 134.3 & 140.8 & 14978 \\
\hline $210^{a, b}$ & 139.2 & 147.5 & 16345 \\
\hline $220^{a, b}$ & 144.1 & 154.1 & 17762 \\
\hline $226.70^{a, b}$ & 147.4 & 158.5 & 18738 \\
\hline $226.70^{a, c}$ & 198.1 & 232.3 & 35473 \\
\hline 230 & 199.6 & 235.2 & 36133 \\
\hline 240 & 203.4 & 243.8 & 38147 \\
\hline 250 & 207.9 & 252.2 & 40204 \\
\hline 260 & 212.8 & 260.4 & 42305 \\
\hline 270 & 218.9 & 268.6 & 44463 \\
\hline 280 & 225.9 & 276.7 & 46687 \\
\hline 290 & 233.7 & 284.7 & 48984 \\
\hline 298.15 & 240.8 & 291.3 & 50917 \\
\hline 300 & 242.4 & 292.8 & 51364 \\
\hline 310 & 251.9 & 300.9 & 53835 \\
\hline 320 & 261.9 & 309.0 & 56403 \\
\hline 330 & 272.3 & 317.3 & 59073 \\
\hline 340 & 282.5 & 325.5 & 61847 \\
\hline 350 & 291.9 & 333.9 & 64721 \\
\hline 360 & 302.4 & 342.3 & 67696 \\
\hline 370 & 311.0 & 350.7 & 70764 \\
\hline 380 & 319.0 & 359.1 & 73914 \\
\hline
\end{tabular}

a Extrapolated. ${ }^{b}$ Solid. c Liquid phase.

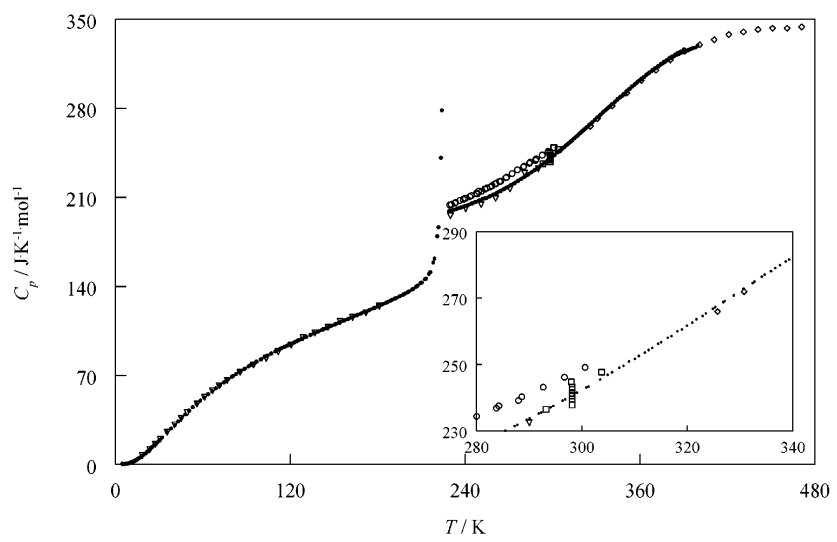

Figure 1. Experimental heat capacity values of 1-hexanol: (•) our data; $(0)$ ref $10 ;(\nabla)$ data from ref $8 ;(\diamond)$ data from ref 9 , these values were measured at $2 \mathrm{MPa} ;(\boldsymbol{\square})$ data from NIST. ${ }^{4}$ The inset gives an enlarged view of the data between $280 \mathrm{~K}$ and $340 \mathrm{~K}$.

Debye heat capacity function $C_{p}=\alpha T^{3}$. The data set was interpolated for every degree, and the derived properties were calculated by numerical integration. The starting values of $\mathrm{S}^{\circ}$ and $\mathrm{H}^{\circ}(\mathrm{T})-\mathrm{H}^{\circ}(0)$ were calculated assuming that below $8 \mathrm{~K}$ the low-temperature limit of the Debyeheat capacity function $C_{p}=\alpha T^{3}$ holds.
Table 7. Experimental Molar Heat Capacities ${ }^{a}$ of 1-Heptanol

\begin{tabular}{|c|c|c|c|c|c|c|c|}
\hline $\mathrm{T}$ & $C_{p}$ & $\mathrm{~T}$ & $C_{p}$ & $\mathrm{~T}$ & $C_{p}$ & $\mathrm{~T}$ & $C_{p}$ \\
\hline 5.31 & 0.44 & 95.61 & 91.19 & 232.78 & 201.10 & 61 & 268.18 \\
\hline 5.4 & 0.56 & 8 & & & 26 & & 70.14 \\
\hline & 0.65 & 10 & 94.53 & & . & & \\
\hline 6.15 & 0.67 & & 95.61 & & 52 & & \\
\hline 6.48 & 0.86 & & 96.11 & & 1349 & & 7 \\
\hline 7.31 & 1.19 & 105.60 & 97.26 & 239. & 322 & 300.38 & 276.64 \\
\hline 7.87 & 1.44 & 108.54 & 98.98 & $\angle 35$ & 6098 & & \\
\hline 8.68 & 1.85 & 111.44 & 100.70 & & 10165 & & \\
\hline 9.23 & 1.97 & 114.34 & 102.18 & 239.65 & 15473 & & \\
\hline 10.13 & 2.56 & 117 & 103.89 & & 22 & & \\
\hline & 2.88 & & 105.61 & & & & \\
\hline & 3.13 & & & & & & \\
\hline & & & & & & & \\
\hline 3.88 & 5.66 & 128.91 & & & & & \\
\hline & 6.01 & & 111.79 & 239.79 & 894 & & 289.5 \\
\hline & & & & & & & \\
\hline 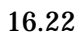 & 8. & & & & & & \\
\hline & 9.78 & & & & & & \\
\hline 2 & 10.55 & 143.59 & & & 436 & & 296.1 \\
\hline & & & & & & & \\
\hline .4 & & & & & 310 & & \\
\hline .1 & 15 & 27 & 12 & & & & \\
\hline 80 & 4 & 5.11 & 7 & & & & \\
\hline & 18.91 & 157.93 & & & & & \\
\hline & & & & & & & \\
\hline 0 & 22.51 & & & & & & \\
\hline .82 & 23 & 166. & 12 & & & & \\
\hline & & 168.95 & 130.67 & & & & 3.0 \\
\hline & & & & & & & \\
\hline & & & & & & & \\
\hline .6 & & & & & & & \\
\hline & & 179 & & & & & \\
\hline & & & & & & & \\
\hline & & & & & & & \\
\hline & 4 & 187 & & & & & \\
\hline .0 & & 189.99 & & & & & \\
\hline & & & & & & & \\
\hline & & & & & & & \\
\hline & & & & & & & \\
\hline & & & & & & & \\
\hline & & 20 & & & & & \\
\hline & & & & & & & \\
\hline & & & & & & & \\
\hline & & & & & & & \\
\hline & 7 & 212.23 & & & & & 2 \\
\hline & & & & & & & \\
\hline & & & & & & & \\
\hline & & & & & & & \\
\hline & & & & & & & \\
\hline & & 223.92 & 172.57 & & 261.95 & 368.24 & 40.6 \\
\hline & & & & & & 369.74 & 341.9 \\
\hline & & & & & & & \\
\hline & & & & & & & \\
\hline
\end{tabular}

a In J $\cdot \mathrm{K}^{-1} \cdot \mathrm{mol}^{-1}$ at temperatures in $\mathrm{K}$.

\section{Results and Discussion}

1-Hexanol. A sample of $6.5 \mathrm{~g}$ was used in CALV. The experimental data are given in Table 2; these are data for a continuous series from $8 \mathrm{~K}$ to $400 \mathrm{~K}$. In Figure 1 the experimental data are plotted, together with the values reported by Kelley and Kalowska et al. ${ }^{10}$ and liquid heat capacity data reported by Fulem et al. ${ }^{9}$ Also plotted are the values of the liquid heat capacity at and around 298.15 K given in the NIST ${ }^{4}$ databank. The literature data correspond, within the error margin, with our results. In Table 3 the enthalpy increments in the melt around the two melting experiments are given. The calculated fractional melting data and the equilibrium temperatures in the melt are given in Table 4. The purities cal culated from these experiments, using the $1 / \mathrm{F}$ range from 1 to 5 , were respectively $99.82 \mathrm{~mol} \%$ and $99.78 \mathrm{~mol} \%$. In Table 1 the 
1326 J ournal of Chemical and Engineering Data, Vol. 48, No. 5, 2003

Table 8. Experimental Enthalpy Increments for 1-Heptanol around the Melting Point

\begin{tabular}{|c|c|c|c|c|c|}
\hline $\mathrm{T}$ & $\mathrm{H}-\mathrm{H}_{\text {start }}$ & $\mathrm{T}$ & $\mathrm{H}-\mathrm{H}_{\text {start }}$ & $\mathrm{T}$ & $\mathrm{H}-\mathrm{H}_{\text {start }}$ \\
\hline K & $\mathrm{J} \cdot \mathrm{mol}^{-1}$ & K & $\mathrm{J} \cdot \mathrm{mol}^{-1}$ & $K$ & $\mathrm{~J} \cdot \mathrm{mol}^{-1}$ \\
\hline \multicolumn{2}{|c|}{$\operatorname{Exp} 1$} & 239.803 & 27092 & 234.828 & 17706 \\
\hline 13.594 & 11262 & 239.805 & 27902 & 236.667 & 18178 \\
\hline 215.567 & 11581 & 239.808 & 28712 & 238.083 & 728 \\
\hline .539 & 11904 & 239.809 & 29523 & 238.918 & 386 \\
\hline 219.509 & 12231 & 239.810 & 30333 & 239.301 & 20127 \\
\hline 221.478 & 12562 & 239.812 & 31144 & 239.485 & 20905 \\
\hline 223.443 & 12897 & 2 & 31 & 23 & 21698 \\
\hline 225.406 & 132 & 40 & 32 & 239.654 & 22498 \\
\hline 227.365 & 13585 & 240.167 & 33511 & 239.698 & 23302 \\
\hline 229.313 & 13939 & 241.435 & 34086 & 239.729 & 24109 \\
\hline 231.243 & & 54 & & 51 & 24917 \\
\hline 233.148 & 146 & 24 & 34 & 23 & 25727 \\
\hline 235.008 & 15079 & 247.189 & 35446 & 239.779 & 26537 \\
\hline 236.741 & 15521 & 249.100 & 35900 & 239.789 & 27348 \\
\hline 238.143 & 16052 & 251.004 & 36 & 239.797 & 28159 \\
\hline 989 & 16 & 03 & & 03 & 70 \\
\hline 359 & 17447 & 254.797 & 37266 & 239.807 & 29782 \\
\hline 239.524 & 18227 & \multicolumn{2}{|c|}{$\operatorname{Exp} 2$} & 239.810 & 30593 \\
\hline 239.613 & 19020 & 212.227 & 137 & 239.811 & 31405 \\
\hline 239.669 & 19821 & 214.605 & & 239.812 & 32217 \\
\hline 7 & 206 & 65 & & 23 & 33 \\
\hline 239.734 & 21430 & 219.304 & 14866 & 239.819 & 33840 \\
\hline 239.753 & 22237 & 221.625 & 15256 & 239.826 & 34651 \\
\hline 239.767 & 230 & 223.924 & & 239.835 & 35462 \\
\hline 239.778 & 23854 & 226.197 & & 240.214 & 36204 \\
\hline 239.787 & 24663 & 228.439 & 16446 & 241.556 & 36768 \\
\hline 39.794 & 25472 & 230.640 & 16854 & 243.487 & 37222 \\
\hline 239.199 & 26282 & 232.782 & 17272 & & \\
\hline
\end{tabular}

Table 9. Equilibrium Temperatures in the Melt and the Reciprocal of the Melted Fraction of 1-Heptanol

\begin{tabular}{|c|c|c|c|c|c|c|c|}
\hline \multicolumn{4}{|c|}{ experiment 1} & \multicolumn{4}{|c|}{ experiment 2} \\
\hline $\mathrm{T} / \mathrm{K}$ & $\mathrm{F}^{-1}$ & $\mathrm{~T} / \mathrm{K}$ & $\mathrm{F}^{-1}$ & $\mathrm{~T} / \mathrm{K}$ & $F^{-1}$ & $\mathrm{~T} / \mathrm{K}$ & $\overline{F^{-1}}$ \\
\hline 239.524 & 6.210 & 239.803 & 1.563 & 485 & 6.386 & 807 & \\
\hline 613 & 4.918 & 305 & 1.4 & 89 & 5.025 & 10 & \\
\hline 239.669 & 4.060 & 239.808 & 1.374 & 239.654 & 4.129 & 811 & 3 \\
\hline 239.707 & 3.453 & 239.809 & 1.295 & 239.698 & 3.499 & 239.812 & 1.2 \\
\hline 239.734 & 3.002 & 239.810 & 1.226 & 239.729 & 3.034 & 239.815 & 1.2 \\
\hline 239.753 & 2.654 & 239.812 & 1.163 & 239.751 & 2.676 & 239.819 & 1. \\
\hline & 2.378 & 319 & 1.106 & 67 & 2.393 & 826 & \\
\hline & 2.154 & 239.840 & 1.055 & 239.779 & 2.164 & 239.835 & .0 \\
\hline 87 & 1.968 & 240.167 & 1.016 & 239.789 & 1.975 & 240.214 & 1.0 \\
\hline 239.794 & 1.811 & 241.436 & 1.000 & 239.797 & 1.816 & 241.557 & 1.00 \\
\hline 239.799 & 1.678 & & & 239.803 & 1.680 & & \\
\hline
\end{tabular}

Table 10. Melting Experiments of 1-Heptanola

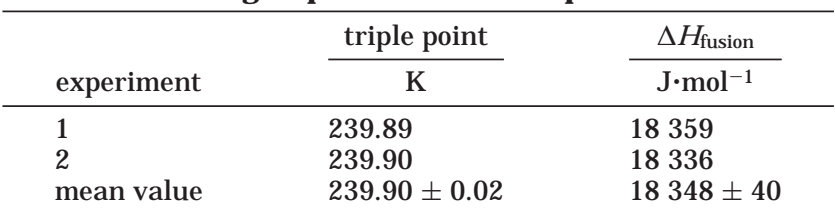

a The following linear fits of the heat capacity were used to calculate the enthalpy of fusion: $C_{p}($ solid $)=\{42.20+0.5219 T\}$ $\mathrm{J} \cdot \mathrm{K}^{-1} \cdot \mathrm{mol}^{-1}$ and $\mathrm{C}_{\mathrm{p}}($ liquid $)=\{137.61+0.4028 \mathrm{~T}\} \mathrm{J} \cdot \mathrm{K}^{-1} \cdot \mathrm{mol}^{-1}$.

mean value is given; the almost exact correspondence between the calorimetric determined purity and the purity measured by analytical means is, in our opinion, due to the very low water content of 1-hexanol. It is to be expected that water does not form an eutectic system with the n-alcohols; we come back to this further on with the measurements of 1-octanol. Table 5 gives the results of the melting experiments and the linear fits of the heat capacity of the solid and liquid phase used as baselines for the calculation. The mean value of the enthalpy of fusion, (16 $729 \pm 35) \mathrm{J} \cdot \mathrm{mol}^{-1}$, is higher than the value reported by Kelley of $15380 \mathrm{~J} \cdot \mathrm{mol}^{-1}$; the triple temperature found in this work, being $(226.70 \pm 0.01) \mathrm{K}$, is $0.9 \mathrm{~K}$ higher than
Table 11. Thermodynamic Properties at Selected Temperatures for 1-Heptanol Molar Mass = $116.20 \mathrm{~g} \mathrm{~mol}^{-1}$

\begin{tabular}{|c|c|c|c|}
\hline $\mathrm{T}$ & $\mathrm{C}_{\mathrm{p}, \mathrm{m}}^{\circ}$ & $\mathrm{S}_{\mathrm{m}}^{\circ}$ & $\Delta \mathrm{H}_{\mathrm{m}}^{\circ}$ \\
\hline $\mathrm{K}$ & $\overline{\mathrm{J} \cdot \mathrm{K}^{-1} \cdot \mathrm{mol}^{-1}}$ & $\overline{\mathrm{J} \cdot \mathrm{K}^{-1} \cdot \mathrm{mol}^{-1}}$ & $\overline{\mathrm{J} \cdot \mathrm{mol}^{-1}}$ \\
\hline 10 & 2.48 & 0.95 & 7.0 \\
\hline 20 & 12.93 & 5.34 & 76.8 \\
\hline 30 & 26.94 & 13.18 & 275 \\
\hline 40 & 40.12 & 22.80 & 612 \\
\hline 50 & 52.11 & 33.07 & 1074 \\
\hline 60 & 62.51 & 43.51 & 1649 \\
\hline 70 & 71.92 & 53.88 & 2322 \\
\hline 80 & 80.02 & 64.01 & 3082 \\
\hline 90 & 87.15 & 73.88 & 3920 \\
\hline 100 & 93.74 & 83.41 & 4826 \\
\hline 110 & 99.85 & 92.65 & 5796 \\
\hline 120 & 105.5 & 101.6 & 6822 \\
\hline 130 & 110.8 & 110.2 & 7904 \\
\hline 140 & 116.0 & 118.6 & 9037 \\
\hline 150 & 120.7 & 126.8 & 10221 \\
\hline 160 & 126.0 & 134.8 & 11456 \\
\hline 170 & 131.2 & 142.6 & 12742 \\
\hline 180 & 136.1 & 150.2 & 14079 \\
\hline 190 & 141.4 & 157.7 & 15466 \\
\hline $200^{a, b}$ & 146.6 & 165.1 & 16906 \\
\hline $210^{a, b}$ & 151.8 & 172.4 & 18398 \\
\hline $220^{a, b}$ & 157.0 & 179.5 & 19942 \\
\hline $230^{a, b}$ & 162.2 & 186.6 & 21539 \\
\hline $239.90^{a, b}$ & 167.4 & 193.6 & 23170 \\
\hline $239.90^{a, c}$ & 234.2 & 270.1 & 41518 \\
\hline 240 & 234.3 & 271.1 & 41294 \\
\hline 250 & 238.7 & 280.1 & 43890 \\
\hline 260 & 244.3 & 289.5 & 46304 \\
\hline 270 & 250.7 & 298.9 & 48778 \\
\hline 280 & 258.9 & 308.1 & 51326 \\
\hline 290 & 266.7 & 317.4 & 53954 \\
\hline 298.15 & 274.0 & 324.9 & 56157 \\
\hline 300 & 275.7 & 326.6 & 56666 \\
\hline 310 & 285.7 & 335.8 & 59473 \\
\hline 320 & 296.3 & 345.0 & 62383 \\
\hline 330 & 307.2 & 354.3 & 65400 \\
\hline 340 & 318.2 & 363.6 & 68528 \\
\hline 350 & 329.0 & 373.0 & 71763 \\
\hline 360 & 339.2 & 382.4 & 75104 \\
\hline
\end{tabular}

the value reported by Kelley. These differences are not within the reported error margins and are probably due to a difference in purity. For the calculation of the entropy and enthal py increments from $0 \mathrm{~K}$, the relation $C_{p}=\alpha T^{3}$ was used to calculate the starting values for a numerical integration at $8 \mathrm{~K}$; $\alpha$ was found to be $1.39 \times 10^{-3}$ $\mathrm{J} \cdot \mathrm{K}^{-4} \cdot \mathrm{mol}^{-1}$. The results are given in Table 6 .

1-Heptanol. We started cooling from room temperature to a temperature below the melting point to assess the thermal behavior. The cooling curve showed an undercooling of $\sim 2.8 \mathrm{~K}$ at a cooling rate of $1.8 \mathrm{~K} \cdot \mathrm{h}^{-1}$. The data series were combined and are presented in the same way as those for 1-hexanol. The temperatures and the heat capacity values are given in Table 7 . The relative enthalpy increments as a function of temperature in the melting range are given in Table 8. A linear fit of the heat capacity of the solid, made between $150 \mathrm{~K}$ and $170 \mathrm{~K}$, was used to calculate the enthalpy of fusion. This fit and a linear fit of the heat capacity of the liquid phase are given together with the result of the calculation of the enthal py of fusion in Table 10. The enthalpy of fusion was found to be (18 $348 \pm 40)$ $\mathrm{J} \cdot \mathrm{mol}^{-1}$, and the triple point temperature was $(239.90 \pm$ $0.02) \mathrm{K}$. The fractional melting curve was calculated by constructing a sigmoid baseline using these fits as starting values for the heat capacity. The calculated $1 / F$ values of the two measurement series in the melt are given in Table 


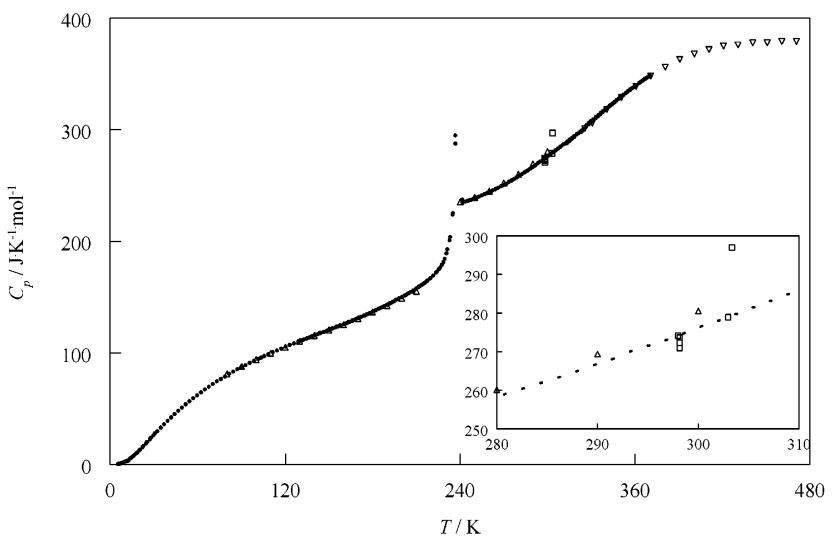

Figure 2. Experimental heat capacity values of 1-heptanol: (0) our data; $(\square)$ ref $4 ;(\nabla)$ data from ref $9 ;(\Delta)$ ref 11 . The inset gives an enlarged view of the data between $280 \mathrm{~K}$ and $310 \mathrm{~K}$.

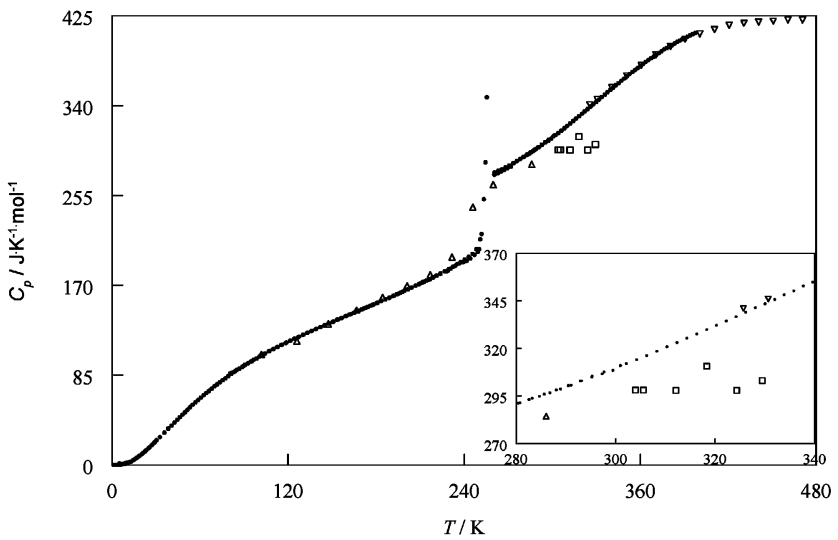

Figure 3. Experimental heat capacity values of 1-octanol: (0) our data; $(\square)$ ref $4 ;(\nabla)$ data from ref $9 ;(\Delta)$ ref 12 . The inset gives an enlarged view of the data between $280 \mathrm{~K}$ and $340 \mathrm{~K}$.

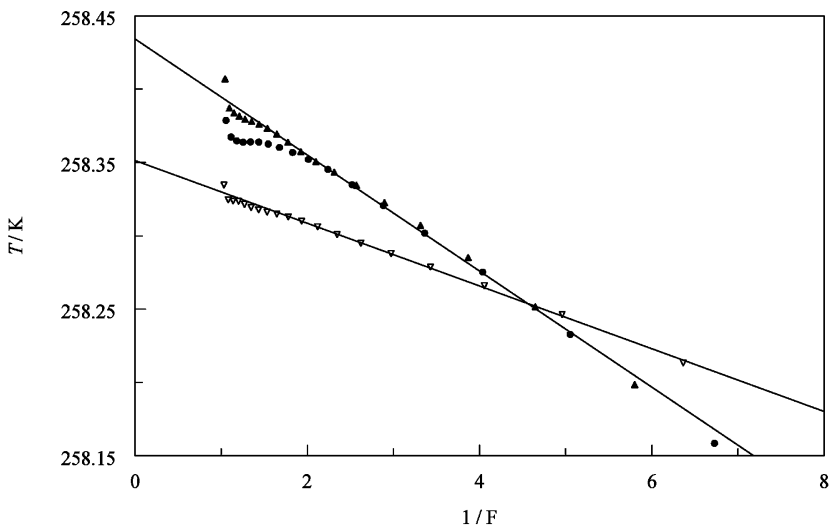

Figure 4. Fractional melting experiments of 1-octanol: $(\mathbf{0}, \mathbf{\Delta})$ measurements on the sample reported in this work; $(\nabla)$ measurement of a sample with a water content of 0.5 wt \%.

9. The calculated purities were respectively $99.79 \mathrm{~mol} \%$ and $99.76 \mathrm{~mol} \%$. The value calculated for $\alpha$ in the relation $C_{p}=\alpha T^{3}$ was $\alpha=2.5 \times 10^{-3} \mathrm{~J} \cdot \mathrm{K}^{-4} \cdot \mathrm{mol}^{-1}$ from the data between $5 \mathrm{~K}$ and $8 \mathrm{~K}$ and was used for calculating the starting values of the numerical calculation of the enthal py and the entropy. The resulting thermodynamic data are given in Table 11. Near the melting point the thermodynamic functions are extrapolated according to the functions given in Table 10. In Figure 2 the experimental heat capacity data are given together with some selected literature data. The correspondence is good; the enthal py of fusion can be compared to the value given by Parks et
Table 12. Experimental Molar Heat Capacitiesa of 1-Octanol

\begin{tabular}{cccccccc}
$\mathrm{T}$ & $\mathrm{C}_{\mathrm{p}}$ & $\mathrm{T}$ & $\mathrm{C}_{\mathrm{p}}$ & $\mathrm{T}$ & $\mathrm{C}_{\mathrm{p}}$ & $\mathrm{T}$ & $\mathrm{C}_{\mathrm{p}}$ \\
\hline 5.51 & 0.55 & 71.67 & 76.25 & 199.21 & 164.61 & 292.88 & 303.04
\end{tabular}

$\begin{array}{llllllll}7.65 & 1.13 & 73.56 & 78.27 & 201.74 & 166.06 & 295.28 & 305.54\end{array}$

$\begin{array}{llllllll}8.67 & 1.38 & 75.46 & 80.21 & 204.25 & 167.79 & 297.66 & 307.64\end{array}$

$\begin{array}{llllllll}9.45 & 1.79 & 77.36 & 82.12 & 206.75 & 169.44 & 300.98 & 311.08\end{array}$

$\begin{array}{llllllll}9.60 & 1.87 & 79.26 & 83.98 & 209.24 & 171.15 & 302.16 & 312.05\end{array}$

$\begin{array}{lllllllll}10.46 & 2.27 & 81.17 & 86.12 & 211.71 & 172.75 & 304.21 & 314.16\end{array}$

$\begin{array}{llllllll}10.49 & 2.20 & 81.87 & 87.31 & 214.16 & 174.25 & 306.25 & 316.36\end{array}$

$\begin{array}{lllllllll}10.59 & 1.99 & 83.09 & 87.87 & 216.60 & 175.77 & 308.28 & 318.62\end{array}$

$\begin{array}{lllllllll}11.31 & 2.15 & 84.00 & 88.68 & 219.03 & 177.39 & 310.30 & 320.94\end{array}$

$\begin{array}{lllllllll}12.02 & 2.64 & 85.01 & 89.74 & 221.44 & 179.06 & 312.31 & 323.19\end{array}$

$\begin{array}{lllllllll}12.51 & 2.70 & 86.87 & 91.24 & 223.84 & 180.79 & 314.32 & 325.48\end{array}$

$\begin{array}{llllllll}13.25 & 3.26 & 86.93 & 91.20 & 227.87 & 183.03 & 316.31 & 327.65\end{array}$

$\begin{array}{lllllllll}14.41 & 4.33 & 88.86 & 92.89 & 228.80 & 183.89 & 318.29 & 329.87\end{array}$

$\begin{array}{lllllllll}14.41 & 4.32 & 89.71 & 93.73 & 230.74 & 185.62 & 320.27 & 332.17\end{array}$

$\begin{array}{lllllllll}15.01 & 4.91 & 90.79 & 94.84 & 233.70 & 188.03 & 322.24 & 334.52\end{array}$

$\begin{array}{lllllllll}16.12 & 5.91 & 92.55 & 96.12 & 236.61 & 190.47 & 324.20 & 336.75\end{array}$

$\begin{array}{lllllllll}16.18 & 5.98 & 92.72 & 96.30 & 239.31 & & 191.90 & 326.16 & 339.10\end{array}$

$\begin{array}{llllllll}16.80 & 6.56 & 94.66 & 97.76 & 241.65 & 193.09 & 328.10 & 341.40\end{array}$

$\begin{array}{llllllll}18.08 & 7.79 & 95.39 & 98.32 & 244.20 & 195.39 & 330.05 & 343.52\end{array}$

$\begin{array}{lllllllll}18.11 & 7.82 & 96.60 & 99.48 & 247.12 & 198.75 & 331.98 & 345.75\end{array}$

$\begin{array}{lllllllll}18.86 & 8.63 & 98.25 & 100.63 & 249.34 & 201.65 & 333.90 & 348.22\end{array}$

$\begin{array}{lllllllll}20.26 & 10.18 & 98.55 & 100.87 & 250.05 & 204.14 & 335.82 & 350.30\end{array}$

$\begin{array}{llllllll}20.30 & 10.22 & 100.49 & 102.53 & 251.91 & 218.67 & 337.73 & 352.81\end{array}$

$\begin{array}{lllllllll}21.07 & 11.09 & 101.11 & 103.05 & 254.58 & 286.37 & 339.63 & 354.92\end{array}$

$\begin{array}{llllllll}22.52 & 12.79 & 103.98 & 105.11 & 256.63 & 581 & 341.53 & 356.95\end{array}$

$\begin{array}{llllllll}22.57 & 12.84 & 106.86 & 107.33 & 257.68 & 2273 & 343.41 & 359.19\end{array}$

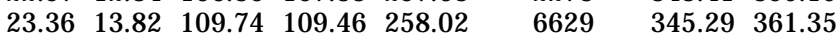

$\begin{array}{llllllll}24.83 & 15.65 & 112.63 & 111.55 & 258.16 & 13069 & 347.17 & 363.47\end{array}$

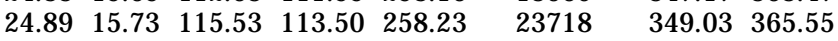

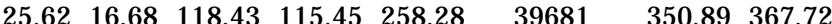

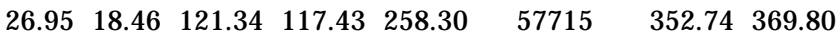

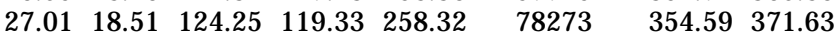

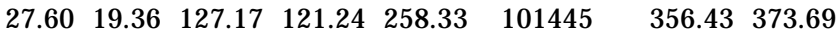

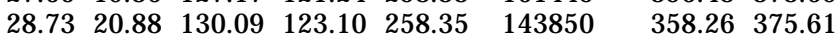

$\begin{array}{llllllll}28.79 & 20.93 & 133.02 & 124.93 & 258.35 & 253752 & 360.09 & 377.59\end{array}$

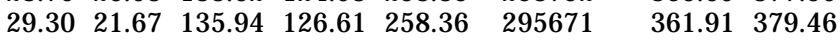

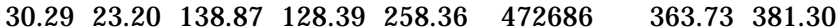

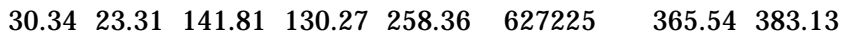

$\begin{array}{llllllll}32.64 & 26.31 & 144.74 & 131.98 & 258.36 & 4113967 & 367.34 & 384.79\end{array}$

$\begin{array}{llllllll}35.67 & 30.50 & 147.68 & 133.74 & 258.36 & 1824897 & 369.14 & 386.39\end{array}$

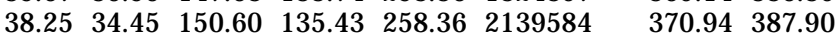

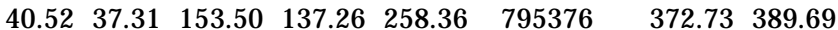

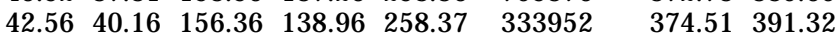

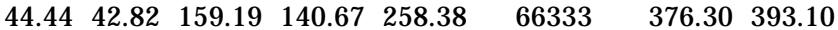

$\begin{array}{llllllll}46.21 & 45.20 & 162.00 & 142.31 & 258.92 & 965 & 378.07 & 394.44\end{array}$

$\begin{array}{llllllll}47.94 & 47.59 & 164.78 & 143.89 & 260.72 & 276.51 & 379.85 & 395.86\end{array}$

$\begin{array}{lllllllll}49.70 & 49.95 & 167.54 & 145.46 & 263.26 & 278.28 & 381.62 & 397.23\end{array}$

$\begin{array}{lllllllll}51.47 & 52.30 & 170.28 & 147.16 & 265.79 & 279.96 & 383.38 & 398.77\end{array}$

$\begin{array}{llllllll}53.25 & 54.69 & 172.99 & 148.67 & 268.30 & 281.74 & 385.15 & 400.21\end{array}$

$\begin{array}{lllllllll}55.05 & 57.19 & 175.69 & 150.31 & 270.80 & 283.47 & 386.92 & 401.56\end{array}$

$\begin{array}{lllllllll}56.86 & 59.30 & 178.37 & 151.92 & 273.30 & 285.37 & 388.68 & 402.87\end{array}$

$\begin{array}{llllllll}58.68 & 61.44 & 181.04 & 153.46 & 275.79 & 287.38 & 390.44 & 404.11\end{array}$

$\begin{array}{llllllll}60.51 & 63.66 & 183.69 & 155.20 & 278.27 & 289.49 & 392.19 & 405.29\end{array}$

$\begin{array}{llllllll}62.35 & 65.86 & 186.32 & 156.65 & 280.73 & 291.59 & 393.95 & 406.53\end{array}$

$\begin{array}{llllllll}64.20 & 68.03 & 188.93 & 158.14 & 283.19 & 293.87 & 395.70 & 407.67\end{array}$

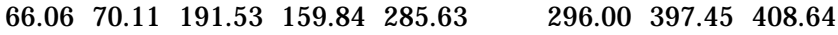

a In $\mathrm{J} \cdot \mathrm{K}^{-1} \cdot \mathrm{mol}^{-1}$ at temperatures in $\mathrm{K}$.

al. $^{11}$ of $18175 \mathrm{~J} \cdot \mathrm{mol}^{-1}$. The difference between that and our value is probably caused by a different choice of baseline. Our value for the absolute entropy at 298.15 K corresponds to the value reported by Parks et al. to within $0.3 \%$.

1-Octanol. The experimental data series between $5 \mathrm{~K}$ and $400 \mathrm{~K}$ are given in Table 12. In Figure 3 all data are plotted together with some literature values. Two melting experiments were performed; the results are given in Table 15 together with the linear fits of the heat capacity of the solid and liquid phase used to calculate the enthalpy of fusion. In Table 13 the data around the melting point are given with the enthalpy increments. The derived thermodynamic properties were calculated by numerical integra- 
1328 J ournal of Chemical and Engineering Data, Vol. 48, No. 5, 2003

Table 13. Experimental Enthalpy Increments for 1-Octanol around the Melting Point

\begin{tabular}{|c|c|c|c|c|c|}
\hline $\mathrm{T}$ & $\mathrm{H}-\mathrm{H}_{\text {start }}$ & $\mathrm{T}$ & $\mathrm{H}-\mathrm{H}_{\text {start }}$ & $\mathrm{T}$ & $\mathrm{H}-\mathrm{H}_{\text {start }}$ \\
\hline K & $\mathrm{J} \cdot \mathrm{mol}^{-1}$ & $K$ & $\mathrm{~J} \cdot \mathrm{mol}^{-1}$ & $\mathrm{~K}$ & $\mathrm{~J} \cdot \mathrm{mol}^{-1}$ \\
\hline \multicolumn{2}{|c|}{ Exp 1} & 258.367 & 24304 & 258.198 & 28343 \\
\hline 50.045 & 144 & 258.379 & 25558 & 258.252 & 29432 \\
\hline 251.907 & 544 & 258.919 & 26696 & 258.285 & 30526 \\
\hline 254.583 & 1214 & 260.722 & 27560 & 258.307 & 31620 \\
\hline 256.628 & 2034 & 263.260 & 28264 & 258.323 & 32714 \\
\hline 257.676 & 3069 & \multicolumn{2}{|c|}{ Exp 2} & 258.334 & 33810 \\
\hline 258.019 & 4249 & 226.780 & 17948 & 258.343 & 34906 \\
\hline 258.158 & 5477 & 229.544 & 18 & 1 & 03 \\
\hline 258.233 & 6732 & 232.289 & 18969 & 2 & 100 \\
\hline 258.275 & 7991 & 235.016 & 19483 & 258.364 & 38198 \\
\hline 258.302 & 9243 & 237.723 & & 258.369 & 297 \\
\hline & 10495 & 24 & & 73 & 40396 \\
\hline 5 & 11749 & 243 & 21 & 76 & 41497 \\
\hline 258.345 & 13003 & 245.737 & 21567 & 258.378 & 42598 \\
\hline 258.352 & 14258 & 248.362 & 22098 & 258.379 & 43697 \\
\hline 258.357 & 15513 & 250.941 & 22636 & 258.382 & 44795 \\
\hline 258.360 & 16768 & 253.387 & & 258.384 & 45893 \\
\hline 23 & 18023 & 255.528 & & $25 \varepsilon$ & 46991 \\
\hline & 19279 & 257.030 & 24 & 258.407 & 48085 \\
\hline 258.364 & 20535 & 257.703 & 25355 & 258.974 & 49060 \\
\hline & & 257.9 & & 260.638 & 49796 \\
\hline 258.365 & 23049 & 258.111 & 27262 & 262.865 & 50409 \\
\hline
\end{tabular}

Table 14. Equilibrium Temperatures in the Melt and the Reciprocal of the Melted Fraction of 1-Octanol

\begin{tabular}{|c|c|c|c|c|c|c|c|}
\hline \multicolumn{4}{|c|}{ experiment 1} & \multicolumn{4}{|c|}{ experiment 2} \\
\hline $\mathrm{T} / \mathrm{K}$ & $\mathrm{F}^{-1}$ & $\mathrm{~T} / \mathrm{K}$ & $\mathrm{F}^{-1}$ & $\mathrm{~T} / \mathrm{K}$ & $\mathrm{F}^{-1}$ & $\mathrm{~T} / \mathrm{K}$ & $\mathrm{F}^{-1}$ \\
\hline 258.019 & 9.910 & 258.360 & 1.677 & 258.111 & 7.692 & 258.369 & $1.64 \varepsilon$ \\
\hline 258.158 & 6.728 & 258.363 & 18 & 258.199 & 5.803 & 3.373 & \\
\hline 258.233 & 5.052 & 258.364 & 1.256 & 258.252 & 4.646 & 258.376 & 1.4 \\
\hline 258.275 & 4.037 & 258.364 & 1.4 & 258.285 & 3.869 & 258.378 & 1.35 \\
\hline 258.302 & 3.364 & 258.364 & 1.340 & 258.307 & 3.313 & 258.380 & 1.27 \\
\hline 258.321 & 2.882 & 258.365 & 1.182 & 258.323 & 2.896 & 258.382 & 1.21 \\
\hline 258.335 & 2.521 & 258.367 & 1.116 & 258.334 & 2.572 & 258.384 & 1.15 \\
\hline 258.345 & 2.240 & 258.379 & 1.057 & 258.343 & 2.313 & 258.387 & 1.095 \\
\hline 258.352 & 2.014 & 258.919 & 1.0 & 258.351 & 2.101 & 258.407 & 1.046 \\
\hline 258.357 & 1.830 & 260.722 & 1.000 & $\begin{array}{l}258.357 \\
258.364\end{array}$ & $\begin{array}{l}1.925 \\
1775\end{array}$ & 262.865 & 1.000 \\
\hline
\end{tabular}

Table 15. Melting Experiments of 1-Octanola

\begin{tabular}{|c|c|c|}
\hline \multirow[b]{2}{*}{ experiment } & triple point & $\Delta \mathrm{H}_{\text {fusion }}$ \\
\hline & $\mathrm{K}$ & $\mathrm{J} \cdot \mathrm{mol}^{-1}$ \\
\hline 1 & 258.43 & 25137 \\
\hline 2 & 258.43 & 25132 \\
\hline mean value & $258.43 \pm 0.02$ & $25135 \pm 40$ \\
\hline
\end{tabular}

a The following linear fits of the heat capacity were used to calculate the enthalpy of fusion: $C_{p}($ solid $)=\{34.94+0.6507 T\}$ $\mathrm{J} \cdot \mathrm{K}^{-1} \cdot \mathrm{mol}^{-1}$ and $\mathrm{C}_{\mathrm{p}}($ liquid $)=\{93.92+0.7001 \mathrm{~T}\} \mathrm{J} \cdot \mathrm{K}^{-1} \cdot \mathrm{mol}^{-1}$.

tion, starting with fitting the heat capacities up to $8 \mathrm{~K}$ to the function $C_{p}=\alpha T^{3} ; \alpha$ was found to be $1.38 \times 10^{-3}$ $\mathrm{J} \cdot \mathrm{K}^{-4} \cdot \mathrm{mol}^{-1}$, and the thermodynamic properties are given in Table 16. The calculated $1 / F$ values of the two measurement series in the melt are given in Table 14. The triple point temperature was $(258.43 \pm 0.02) \mathrm{K}$, and the enthal py of fusion was $(25135 \pm 40) \mathrm{J} \cdot \mathrm{mol}^{-1}$. In Figure 4 the equilibrium temperatures in the melt are plotted against the reciprocal of the melted fraction. The purity calculated from this curve was $99.82 \mathrm{~mol} \%$. In the same figure the measurement on a sample containing 0.5 wt \% water is given. The measurements on this sample were not used after we found the high water content, but it is interesting to see that, while the triple point is, as expected, lower than the triple point of the more pure sample, the purity calculated from this measurement is even better than that of the pure sample. This confirms that water does not form
Table 16. Thermodynamic Properties at Selected Temperatures for 1-Octanol Molar Mass $=130.33 \mathrm{~g} \cdot \mathrm{mol}^{-1}$

\begin{tabular}{|c|c|c|c|}
\hline $\mathrm{T}$ & $\mathrm{C}_{\mathrm{p}, \mathrm{m}}^{\circ}$ & $\mathrm{S}_{\mathrm{m}}^{\circ}$ & $\Delta \mathrm{H}_{\mathrm{m}}^{\circ}$ \\
\hline K & $\overline{\mathrm{J} \cdot \mathrm{K}^{-1} \cdot \mathrm{mol}^{-1}}$ & $\overline{\mathrm{J} \cdot \mathrm{K}^{-1} \cdot \mathrm{mol}^{-1}}$ & $\mathrm{~J} \cdot \mathrm{mol}^{-1}$ \\
\hline 10 & 2.14 & 0.46 & 3.5 \\
\hline 20 & 9.90 & 3.71 & 54.9 \\
\hline 30 & 22.74 & 10.00 & 214 \\
\hline 40 & 36.64 & 18.40 & 509 \\
\hline 50 & 50.35 & 28.03 & 944 \\
\hline 60 & 63.04 & 38.37 & 1512 \\
\hline 70 & 74.50 & 48.96 & 2201 \\
\hline 80 & 84.76 & 59.59 & 2998 \\
\hline 90 & 94.02 & 70.15 & 3895 \\
\hline 100 & 102.1 & 80.45 & 4874 \\
\hline 110 & 109.7 & 90.56 & 5935 \\
\hline 120 & 116.5 & 100.4 & 7067 \\
\hline 130 & 123.0 & 110.0 & 8265 \\
\hline 140 & 129.1 & 119.3 & 9525 \\
\hline 150 & 135.1 & 128.4 & 10847 \\
\hline 160 & 141.2 & 137.4 & 12228 \\
\hline 170 & 147.0 & 146.1 & 13668 \\
\hline 180 & 152.9 & 154.7 & 15167 \\
\hline 190 & 158.8 & 163.1 & 16726 \\
\hline 200 & 165.1 & 171.4 & 18346 \\
\hline 210 & 171.7 & 179.6 & 20029 \\
\hline 220 & 178.1 & 187.7 & 21777 \\
\hline 230 & 184.6 & 195.8 & 23590 \\
\hline 240 & 191.1 & 203.8 & 25469 \\
\hline $250^{a}$ & 197.6 & 211.7 & 27413 \\
\hline $258.43^{a, b}$ & 203.1 & 218.4 & 29102 \\
\hline $258.43^{a, c}$ & 274.9 & 315.6 & 54234 \\
\hline 260 & 276.0 & 317.3 & 54666 \\
\hline 270 & 283.0 & 327.8 & 57461 \\
\hline 280 & 290.6 & 338.3 & 60338 \\
\hline 290 & 300.0 & 348.7 & 63292 \\
\hline 298.15 & 308.1 & 357.1 & 65772 \\
\hline 300 & 310.1 & 359.0 & 66343 \\
\hline 310 & 320.6 & 369.4 & 69495 \\
\hline 320 & 331.9 & 379.7 & 72757 \\
\hline 330 & 343.5 & 390.1 & 76135 \\
\hline 340 & 355.3 & 400.5 & 79629 \\
\hline 350 & 366.7 & 411.0 & 83239 \\
\hline 360 & 377.5 & 421.5 & 86960 \\
\hline 370 & 387.1 & 432.0 & 90785 \\
\hline 380 & 396.0 & 442.4 & 94702 \\
\hline 390 & 403.8 & 452.8 & 98702 \\
\hline
\end{tabular}

${ }^{a}$ Extrapolated. ${ }^{b}$ Solid. ${ }^{c}$ Liquid phase.

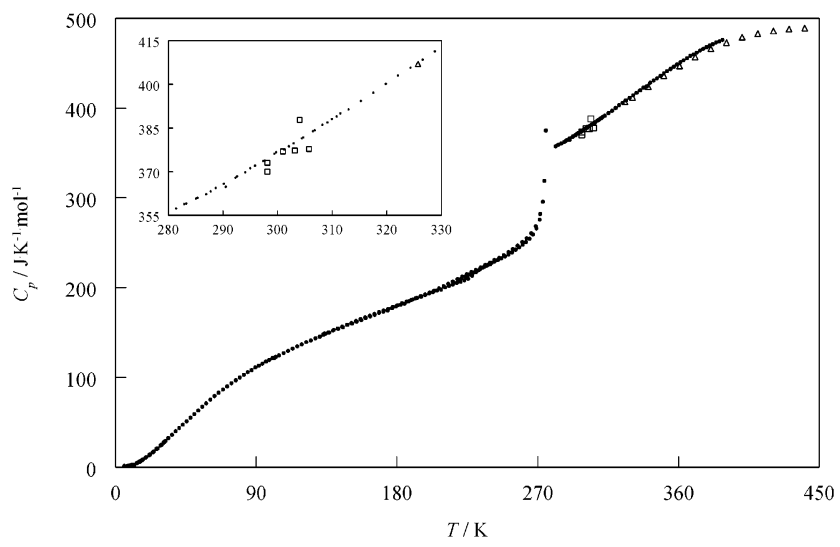

Figure 5. Experimental heat capacity values of 1-decanol: (0) our data; $(\square)$ ref $4 ;(\triangle)$ data from ref 9 . The inset gives an enlarged view of the data between $280 \mathrm{~K}$ and $330 \mathrm{~K}$.

a eutectic system with the al cohol and that the cal orimetric purity determination of the $n$-alcohols can be performed only on very dry samples.

1-Decanol. The cooling curve showed an undercooling of the crystallization of $0.8 \mathrm{~K}$. The continuous set of experimental data between $5 \mathrm{~K}$ and $388 \mathrm{~K}$ is given in Table 
Table 17. Experimental Molar Heat Capacities ${ }^{\mathrm{a}}$ of 1-Decanol

\begin{tabular}{|c|c|c|c|c|c|c|c|}
\hline $\mathrm{T}$ & $C_{p}$ & $\mathrm{~T}$ & $C_{p}$ & $T$ & $C_{p}$ & $T$ & $C_{p}$ \\
\hline 5.55 & 0.74 & 60.70 & 75.26 & 183.30 & 182.52 & 280.00 & 0176 \\
\hline 5.64 & 1.03 & 6334 & 79.18 & 186.25 & 184.33 & 280.86 & 657 \\
\hline 5.6 & 1.07 & 1 & 82.81 & 189.19 & $1 \varepsilon$ & 91 & \\
\hline 6.16 & 0.68 & 68.71 & 86.35 & 192.14 & & 285.35 & \\
\hline 6.50 & 0.83 & 71.43 & 89.88 & 195.09 & 190.24 & 287.77 & 20 \\
\hline 6.70 & 0.84 & 74.18 & 93.36 & 198.03 & 192.29 & 290.19 & \\
\hline 7.37 & 1.13 & 76.92 & 96. & 200.98 & & & \\
\hline 8.64 & 1.81 & 79.58 & 99.90 & & & 99 & \\
\hline 8.65 & 1.58 & 82.14 & 102.85 & 206.87 & 199.08 & 297.37 & \\
\hline 8.66 & 1.55 & 84.63 & 105.79 & 209.82 & & & \\
\hline ר & 2.13 & & & & & & \\
\hline 0.31 & 2.28 & 89.41 & & 215.71 & & 46 & \\
\hline 43 & 2.39 & 91.72 & & 218.67 & 20 & 306.80 & \\
\hline 1.82 & 2.42 & 93.98 & & & & & \\
\hline & 2.5 & & & & & & \\
\hline 12.05 & 2.55 & 98.36 & 11 & 227.54 & & & \\
\hline & 4.40 & 100.49 & 121.62 & 230.49 & & L2.97 & \\
\hline & 4.68 & & & & & & \\
\hline 1 & 4.72 & & & & & & \\
\hline 15.31 & 5.87 & 104.62 & 124.55 & 23 & 227 & 81 & \\
\hline & 6.24 & & & & & & \\
\hline .7 & 6.38 & & & & & & \\
\hline $17.1 \mathrm{~s}$ & 7.90 & $1]$ & 13 & & & & \\
\hline 17.63 & 8.42 & 3 & 13 & 18 & & 78 & \\
\hline & 8.50 & & & & & & \\
\hline 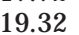 & 10.35 & 122 & 13 & & & & \\
\hline 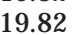 & 11.05 & 124.95 & 141.17 & & & & \\
\hline 92 & 11.18 & 127.87 & 143.57 & 26 & 255 & 63 & \\
\hline & & & & & & & \\
\hline & 13. & & & & & & \\
\hline & 14.0 & 13 & & 27 & 282 & & \\
\hline 2 & 30 & 13 & & 274.26 & 318.87 & 33 & \\
\hline & & & & & & & \\
\hline & & & & & 91 & & \\
\hline & & & & & 1692 & & \\
\hline & $\angle U$ & & & & 5009 & & \\
\hline & & & & & & & \\
\hline & & & & & & & \\
\hline & 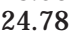 & & & & 358 & & \\
\hline & & & & & 56015 & & \\
\hline & & & & & & & \\
\hline & & & & & & & \\
\hline & & & & & 15 & & \\
\hline & & & & & & & \\
\hline & & & & & & & \\
\hline & & & & & & & \\
\hline & & & & & & & \\
\hline & & & & & & & 405. \\
\hline & & & & & & & \\
\hline & 5500 & & & & & & \\
\hline 50 & & & & & & & \\
\hline 52.95 & & & & 27 & 952075 & 388.12 & +1 \\
\hline
\end{tabular}

$\begin{array}{llllll}55.50 & 67.11 & 177.40 & 178.37 & 279.94 & 273491\end{array}$

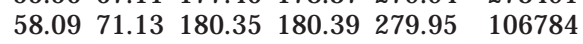

a In J $\cdot \mathrm{K}^{-1} \cdot \mathrm{mol}^{-1}$ at temperatures in $\mathrm{K}$.

17. In Table 18 the data of the two melting experiments are given. The calculated fractional melt data of these series are given in Table 19. The results of the melting experiments and the linear fits of the heat capacity of the solid and liquid phase used in the calculation are given in Table 20. The purity calculated from the fractional melting experiments is $99.78 \mathrm{~mol} \%$ using values of $1 / F$ up to 5 . As the curve of the equilibrium temperature in the melt against the reciprocal of the melted fraction is not linear above this value, the use of the model assuming eutectic behavior between the main component and the impurity is questionable. However, the value calculated for the purity does correspond very well to the value found by analytical means. The triple point temperature (at $1 / \mathrm{F}=$ 0 ) was found to be $(280.00 \pm 0.02) \mathrm{K}$, and the mean
Table 18. Experimental Enthalpy Increments for 1-Decanol around the Melting Point

\begin{tabular}{|c|c|c|c|c|c|}
\hline $\mathrm{T}$ & $\mathrm{H}-\mathrm{H}_{\text {start }}$ & $\mathrm{T}$ & $\mathrm{H}-\mathrm{H}_{\text {start }}$ & $\mathrm{T}$ & $\mathrm{H}-\mathrm{H}_{\text {start }}$ \\
\hline$K$ & $\mathrm{~J} \cdot \mathrm{mol}^{-}$ & $K$ & $\mathrm{~J} \cdot \mathrm{mol}^{-}$ & K & $\mathrm{J} \cdot \mathrm{mol}^{-}$ \\
\hline \multicolumn{2}{|c|}{$\operatorname{Exp} 1$} & 279.890 & 46372 & 265.854 & 26161 \\
\hline 242.169 & 24428 & 279.900 & 47512 & 268.731 & 26922 \\
\hline 244.489 & 24960 & 279.908 & 48652 & 271.553 & 27699 \\
\hline 246.795 & 25495 & 279.915 & 93 & 274.255 & 28509 \\
\hline 249.091 & 26031 & 279.921 & 50 & 276.391 & 29469 \\
\hline 251.374 & 26570 & 279.927 & 52075 & 277.870 & 30605 \\
\hline 253.642 & 27110 & 279.931 & & 278.910 & 31857 \\
\hline 255.896 & 27 & 34 & & 27 & 44 \\
\hline 58.139 & 281 & 27 & & & 18 \\
\hline 260.368 & 28748 & 27 & & 279.760 & 220 \\
\hline 262.582 & 29300 & 279.941 & & 279.818 & 37735 \\
\hline 264.783 & 29 & $27 \subseteq$ & & & 56 \\
\hline 266.966 & 30417 & 279.9 & 60 & 279. & 179 \\
\hline 269.125 & 30 & 279.949 & & 279.892 & 42306 \\
\hline 271.249 & 31558 & 279.951 & 62 & 279.904 & 43833 \\
\hline 273.314 & & 279.954 & & 279.914 & 45360 \\
\hline 215 & 32 & & & & 389 \\
\hline 276.652 & 33537 & 279.966 & 65 & 27 & 48417 \\
\hline 277.732 & 34390 & 280.257 & 66 & 279.930 & 49946 \\
\hline 278.642 & 35287 & 281.456 & 67657 & 279.932 & 51475 \\
\hline 279.207 & 362 & \multicolumn{2}{|c|}{$\operatorname{Exp} 2$} & 279.933 & 53005 \\
\hline 279.486 & 373 & 242.316 & 20426 & 279.934 & 54535 \\
\hline 279.633 & 38444 & 245.268 & & 279.937 & 56064 \\
\hline 279.721 & 39562 & 248.223 & 21803 & 279.939 & 57594 \\
\hline & 40689 & 251.179 & & 279.942 & \\
\hline 279.815 & 41820 & 254.128 & & & 60652 \\
\hline & 42956 & 257.069 & & 279.997 & 62171 \\
\hline 279.863 & 44094 & 260.007 & 24668 & 280.862 & 63470 \\
\hline 279.879 & 45233 & 262.940 & 25410 & 282.909 & 64452 \\
\hline
\end{tabular}

Table 19. Equilibrium Temperatures in the Melt and the Reciprocal of the Melted Fraction of 1-Decanol

\begin{tabular}{|c|c|c|c|c|c|c|c|}
\hline \multicolumn{4}{|c|}{ experiment 1} & \multicolumn{4}{|c|}{ experiment 2} \\
\hline$T / K$ & $\mathrm{~F}^{-1}$ & $\mathrm{~T} / \mathrm{K}$ & $\mathrm{F}^{-1}$ & $\mathrm{~T} / \mathrm{K}$ & $\mathrm{F}^{-1}$ & $\mathrm{~T} / \mathrm{K}$ & $\overline{F^{-1}}$ \\
\hline 279.633 & 6.651 & 279.934 & 1.611 & 279.657 & 6.674 & 279.932 & 1.549 \\
\hline 279.721 & 5.468 & 279.937 & 1.527 & 279.760 & 5.164 & 279.933 & 1.447 \\
\hline 279.777 & 4.632 & 279.939 & 1.452 & 279.818 & 4.198 & 279.934 & 1.358 \\
\hline 279.815 & 4.013 & 279.941 & 1.384 & 279.853 & 3.532 & 279.937 & 1.279 \\
\hline 279.843 & 3.537 & 279.943 & 1.322 & 279.876 & 3.047 & 279.939 & 1.209 \\
\hline 279.863 & 3.161 & 279.946 & 1.265 & 279.892 & 2.678 & 279.942 & 1.146 \\
\hline 279.879 & 2.857 & 279.949 & 1.213 & 279.904 & 2.388 & 279.952 & 1.089 \\
\hline 279.891 & 2.605 & 279.951 & 1.165 & 279.914 & 2.155 & 279.997 & 1.039 \\
\hline 279.900 & 2.395 & 279.955 & 1.121 & 279.921 & 1.963 & 280.862 & 1.008 \\
\hline 279.908 & 2.215 & 279.959 & 1.080 & 279.926 & 1.803 & 282.909 & 1.000 \\
\hline 279.915 & 2.061 & 279.966 & 1.042 & 279.930 & 1.666 & & \\
\hline
\end{tabular}

$\begin{array}{llll}279.921 & 1.926 & 280.257 & 1.012 \\ 279.927 & 1.808 & 281.457 & 1.000\end{array}$

279.9311 .704

Table 20. Melting Experiments of 1-Decanola

\begin{tabular}{|c|c|c|}
\hline & triple point & $\Delta H_{\text {fusion }}$ \\
\hline experiment & K & $\mathrm{J} \cdot \mathrm{mol}^{-1}$ \\
\hline $\begin{array}{l}1 \\
2 \\
\text { mean value }\end{array}$ & $\begin{array}{l}280.00 \\
280.00 \\
280.00 \pm 0.02\end{array}$ & $\begin{array}{l}33522 \\
33817 \\
33670 \pm 150\end{array}$ \\
\hline
\end{tabular}

a The following linear fits of the heat capacity were used to calculate the enthalpy of fusion: $C_{p}($ solid $)=\{14.01+0.8933 T\}$ $\mathrm{J} \cdot \mathrm{K}^{-1} \cdot \mathrm{mol}^{-1}$ and $\mathrm{C}_{\mathrm{p}}($ liquid $)=\{51.63+1.0832 \mathrm{~T}\} \mathrm{J} \cdot \mathrm{K}^{-1} \cdot \mathrm{mol}^{-1}$.

enthalpy of fusion was $33670 \mathrm{~J} \cdot \mathrm{mol}^{-1}$, which is quite different from the value given in the NIST Databook ${ }^{4}$ of $37660 \mathrm{~J} \cdot \mathrm{mol}^{-1}$. In Figure 5 the experimental data are given together with literature data. The inset gives the data range around $298.15 \mathrm{~K}$ and the literature data mentioned in the NIST Databook. Nolarge deviations were found; the correspondence with the data given by $\mathrm{Fulem}^{9}$ is good even considering that these data were measured under a pressure of $2 \mathrm{MPa}$. 
1330 J ournal of Chemical and Engineering Data, Vol. 48, No. 5, 2003

Table 21. Thermodynamic Properties at Selected Temperatures for 1-Decanol Molar Mass $=158.28 \mathrm{~g} \cdot \mathrm{mol}^{-1}$

\begin{tabular}{|c|c|c|c|}
\hline $\mathrm{T}$ & $\mathrm{C}_{\mathrm{p}, \mathrm{m}}^{\circ}$ & $\mathrm{S}_{\mathrm{m}}^{\circ}$ & $\Delta \mathrm{H}_{\mathrm{m}}^{\circ}$ \\
\hline K & $\mathrm{J} \cdot \mathrm{K}^{-1} \cdot \mathrm{mol}^{-1}$ & $\overline{\mathrm{J} \cdot \mathrm{K}^{-1} \cdot \mathrm{mol}^{-1}}$ & $\mathrm{~J} \cdot \mathrm{mol}^{-1}$ \\
\hline 10 & 2.17 & 0.88 & 6.48 \\
\hline 20 & 11.29 & 4.59 & 65.37 \\
\hline 30 & 25.66 & 11.81 & 248 \\
\hline 40 & 42.38 & 21.58 & 592 \\
\hline 50 & 58.34 & 32.73 & 1095 \\
\hline 60 & 74.16 & 44.78 & 1758 \\
\hline 70 & 88.03 & 57.29 & 2571 \\
\hline 80 & 100.4 & 69.86 & 3514 \\
\hline 90 & 111.6 & 82.33 & 4573 \\
\hline 100 & 121.1 & 94.56 & 5736 \\
\hline 110 & 129.2 & 106.5 & 6987 \\
\hline 120 & 137.4 & 118.1 & 8321 \\
\hline 130 & 144.8 & 129.4 & 9734 \\
\hline 140 & 153.3 & 140.4 & 11224 \\
\hline 150 & 159.7 & 151.2 & 12787 \\
\hline 160 & 166.9 & 161.8 & 14422 \\
\hline 170 & 173.5 & 172.1 & 16123 \\
\hline 180 & 180.2 & 182.2 & 17891 \\
\hline 190 & 186.8 & 192.1 & 19726 \\
\hline 200 & 193.7 & 201.9 & 21628 \\
\hline 210 & 201.7 & 211.5 & 23604 \\
\hline 220 & 210.6 & 221.1 & 25665 \\
\hline 230 & 219.3 & 230.6 & 27816 \\
\hline 240 & 228.4 & 240.2 & 30054 \\
\hline 250 & 237.3 & 249.7 & 32383 \\
\hline $260^{a, b}$ & 246.3 & 259.1 & 34801 \\
\hline $270^{a, b}$ & 255.2 & 268.6 & 37308 \\
\hline $280^{a, b}$ & 264.1 & 278.1 & 39904 \\
\hline $280^{a, c}$ & 354.9 & 398.9 & 73721 \\
\hline 290 & 365.8 & 411.5 & 77325 \\
\hline 298.15 & 374.6 & 421.8 & 80342 \\
\hline 300 & 377.0 & 424.1 & 81037 \\
\hline 310 & 388.0 & 436.6 & 84862 \\
\hline 320 & 400.4 & 449.2 & 88804 \\
\hline 330 & 412.9 & 461.7 & 92870 \\
\hline 340 & 424.6 & 474.2 & 97058 \\
\hline 350 & 437.8 & 486.7 & 101370 \\
\hline 360 & 449.7 & 499.2 & 105807 \\
\hline 370 & 460.1 & 511.6 & 110356 \\
\hline 380 & 469.7 & 524.0 & 115005 \\
\hline
\end{tabular}

a Extrapolated. ${ }^{b}$ Solid. ${ }^{c}$ Liquid phase.

Thermodynamic properties resulting from numerical calculation are given in Table 21, $\alpha$ for the relation $C_{p}=$ $\alpha T^{3}$ was calculated from the data between $5 \mathrm{~K}$ and $9 \mathrm{~K}$ to be $1.4 \times 10^{-3} \mathrm{~J} \cdot \mathrm{K}^{-4} \cdot \mathrm{mol}^{-1}$. The data were interpolated for every degree from $9 \mathrm{~K}$ on. Near the melting point, the thermodynamic functions were extrapolated according to the fits given in Table 20 .

Correlation of the Liquid Heat Capacity Data. In the previous articles on the 1-alcohols, we presented correlation functions for the heat capacities of the liquid 1-al cohols. In the first article, concerning the heat capacity data of the alcohols with the number of carbon atoms in the chain of 18, 19, 20, and 22, a simple function with three variables could be used. After the data set was extended with the compounds with carbon numbers $12,13,15$, and 17 , the number of variables was increased to four. When we included the data presented in this article, again the number of variables had to be increased to obtain the best fit for the whole set. The following correlation function

$$
\begin{aligned}
\mathrm{C}_{p, I}(\mathrm{n}, \mathrm{T}) / \mathrm{J} \cdot \mathrm{K}^{-1} \cdot \mathrm{mol}^{-1}= \\
\quad\left(a_{0}+\mathrm{a}_{1} \mathrm{n}+\mathrm{a}_{2} \mathrm{nT}+\mathrm{a}_{3} T+\mathrm{a}_{4} T+\mathrm{a}_{5} / \mathrm{T}+\mathrm{a}_{6} \mathrm{~T}^{2}\right)
\end{aligned}
$$

was fitted for all data measured on the compounds with the number of carbon atoms in the chain ranging from 6 to 22. The total number of data triplets, consisting of mean temperature, mean heat capacity over the measuring interval, and the number of carbon atoms in the chain (n), was $\mathrm{N}=702$. The correlation function found was

$$
\begin{aligned}
& C_{p, I}(n, T) / J \cdot K^{-1} \cdot \mathrm{mol}^{-1}=-3163.5+21.0156 n+ \\
& \quad 0.04223 n T+9.89055 T+322705.7 / T-0.0093225 T^{2}
\end{aligned}
$$

The mean absolute percentage deviation of the function with the experimental data was $0.22 \%$, and the standard deviation was $1.26 \mathrm{~J} \cdot \mathrm{K}^{-1} \cdot \mathrm{mol}^{-1}$. The temperature dependence of the heat capacity of the pure liquid n-alcohols is quite complex, as described by Zábranský. ${ }^{13}$ This is reflected in the number of parameters needed for the correlation function.

Correlation of the Entropy at $360 \mathrm{~K}$ and at 298.15 K. In Table 22 the experimental absolute entropy values at $360 \mathrm{~K}$ are given for the alcohols with carbon numbers $6,7,8,9,12,13,18,19,20$, and 22 . A linear fit as a function the number of carbon atoms in the molecules resulted in the correlation

$$
\mathrm{S}^{\circ}(360 \mathrm{~K}, \mathrm{n})=(111.86+38.613 \mathrm{n}) \mathrm{J} \cdot \mathrm{K}^{-1} \cdot \mathrm{mol}^{-1}
$$

The standard deviation of this equation is $0.82 \mathrm{~J} \cdot \mathrm{K}^{-1} \cdot \mathrm{mol}^{-1}$, and the maximum deviation is $0.36 \%$ for $n=6$. Using the above-mentioned correlation for the heat capacity of the

\begin{tabular}{|c|c|c|c|c|c|c|c|}
\hline compound & $n^{b}$ & $\begin{array}{l}\mathrm{S}_{\mathrm{abs}}(360 \mathrm{~K}) \\
\frac{\mathrm{meas}}{1 \cdot \mathrm{K}^{-1} \cdot \mathrm{mol}^{-1}}\end{array}$ & $\begin{array}{l}\mathrm{S}_{\mathrm{abs}}(360 \mathrm{~K}) \\
\text { correlated } \\
\cdot \mathrm{K}^{-1} \cdot \mathrm{mol}^{-1}\end{array}$ & dev & $\begin{array}{c}\mathrm{S}_{\mathrm{abs}}(298.15 \mathrm{~K})^{\mathrm{c}} \\
\frac{\mathrm{meas}}{1 \cdot \mathrm{K}^{-1} \cdot \mathrm{mol}^{-1}}\end{array}$ & $\begin{array}{c}\text { Sabs }(298.15 \mathrm{~K}) \\
\text { correlated } \\
\cdot \mathrm{K}^{-1} \cdot \mathrm{mol}^{-1}\end{array}$ & $\frac{\mathrm{dev}}{\%}$ \\
\hline 1-hexanol & 6 & 342.3 & 343.5 & -0.36 & 291.3 & 2926 & -0.43 \\
\hline 1-heptanol & 7 & 382.4 & 382.1 & 0.07 & 324.9 & 324.6 & 0.09 \\
\hline 1-octanol & 8 & 421.5 & 420.8 & 0.17 & 357.1 & 356.6 & 0.13 \\
\hline 1-decanol & 10 & 498.8 & 498.0 & 0.16 & 421.8 & 420.7 & 0.26 \\
\hline 1-dodecanol & 12 & 574.8 & 575.2 & -0.08 & 484.3 & 484.8 & -0.10 \\
\hline 1-tridecanol & 13 & 613.6 & 613.8 & -0.04 & 516.5 & 516.8 & -0.05 \\
\hline 1-octadecanol & 18 & 806.8 & 806.9 & -0.01 & 676.9 & 677.0 & -0.01 \\
\hline 1-nonadecanol & 19 & 845.8 & 845.5 & 0.04 & 709.3 & 709.0 & 0.05 \\
\hline 1-eicsanol & 20 & 885.1 & 884.1 & 0.11 & 742.0 & 741.0 & 0.13 \\
\hline 1-docosanol & 22 & 960.2 & 961.3 & -0.12 & 804.0 & 805.1 & -0.14 \\
\hline
\end{tabular}
liquid phase, the absolute entropy at $298.15 \mathrm{~K}$ was also calculated. At this temperature the alcohols with carbon number 12 and higher are in the solid phase, so the

Table 22. Measured and Correlated Absolute Entropies of the Liquid 1-Alcohols at $289.15 \mathrm{~K}$ and $360 \mathrm{~K}^{\mathrm{a}}$

a The correlations are $\mathrm{S}_{\mathrm{abs}}(360 \mathrm{~K})=(111.86+38.613 \mathrm{n}) \mathrm{J} \cdot \mathrm{K}^{-1} \cdot \mathrm{mol}^{-1}$ and $\mathrm{S}_{\mathrm{abs}}(298.15 \mathrm{~K})=(100.35+32.035 \mathrm{n}) \mathrm{J} \cdot \mathrm{K}^{-1} \cdot \mathrm{mol}^{-1} \cdot{ }^{\mathrm{b}} \mathrm{Number}$ of carbon atoms. ' For the compounds with $n=12$ to $n=22$, the melting point is above $298.15 \mathrm{~K} ; \mathrm{S}_{\text {abs }}(298.15 \mathrm{~K})$ of the hypothetical liquid was calculated from $\mathrm{S}_{\mathrm{abs}}(360 \mathrm{~K})$ using the correlation function for $\mathrm{C}_{\mathrm{p}}(\mathrm{I})$. 
correlation for the entropy is made for the hypothetical liquids at this temperature. The correlation found was

$$
\mathrm{S}_{\text {abs }}(298.15 \mathrm{~K})=(100.35+32.035 \mathrm{n}) \mathrm{J} \cdot \mathrm{K}^{-1} \cdot \mathrm{mol}^{-1}
$$

The standard deviation of this fit was $0.86 \mathrm{~J} \cdot \mathrm{K}^{-1} \cdot \mathrm{mol}^{-1}$.

\section{Literature Cited}

(1) van Miltenburg, J . C.; Oonk, A. J .; Ventola, L. Heat Capacities and Derived Thermodynamic Functions of 1-Octadecanol, 1-N onadecanol, 1-Eicosanol, and 1-Docosanol Between $10 \mathrm{~K}$ and $370 \mathrm{~K}$. J. Chem. Eng. Data 2001, 46, 90-97.

(2) van Miltenburg, J . C.; van den Berg, G. J . K.; Ramirez, M. Heat Capacities and Derived Thermodynamic F unctions of 1-Dodecano and 1-Tridecanol between $10 \mathrm{~K}$ and $370 \mathrm{~K}$ and Heat Capacities of 1-Pentadecanol and 1-Heptadecanol between $300 \mathrm{~K}$ and $380 \mathrm{~K}$ and Correlation for the Heat Capacity and the Entropy of liquid n-Alcohols. J . Chem. Eng. Data 2003, 48, 36-43.

(3) Zábranský, M.; Rưžička, V., J r.; Majer, V.; Domalski, E. S. Heat Capacity of Liquids: Volume II, Critical Review and Recommended Values. J. Phys. Chem. Ref. Data, Monograph 61996. Zábranský, M.; Rưžička, V.; Domalski, E. S. Heat Capacity of Liquids: Critical Review and Recommended Values Supplement I. J. Phys. Chem. Ref. Data 2001, 30, 1199-1689.

(4) NIST Chemistry Webbook, http://webbook.nist.gov/chemistry.

(5) van Miltenburg, J . C.; van Berg, G. J . K.; van den Bommel, M. J Construction of an Adiabatic Calorimeter. Measurement of the Molar Heat Capacity of Synthetic Sapphire and of n-Heptane. J . Chem. Thermodyn. 1987, 19, 1129-1137.

(6) van Miltenburg, J . C.; van Genderen, A. C. G.; van den Berg, G. J. K. Design I mprovements in Adiabatic Calorimetry. The Heat
Capacity of Cholesterol Between 10 and $425 \mathrm{~K}$. Thermochim. Acta 1998, 319, 151-162.

(7) Preston-Thomas, H. The International Temperature Scale of 1990 (ITS-90). Metrologia 1990, 27, 3-10.

(8) Kelley, K. K. The Heat Capacities of Ethyl and Hexyl Alcohols from $16 \mathrm{~K}$ to $298 \mathrm{~K}$ and the Corresponding Entropies and Free Energies. J . Am. Chem. Soc. 1929, 51, 779-781.

(9) Fulem, M.; Růžička, K.; Růžička, V. Heat Capacities of Alkanols. Part I. Selected 1-Alkanols $C_{2}$ to $C_{10}$ at Elevated Temperatures and Pressures. Thermochim. Acta 2002, 382, 119-128.

(10) Kalinowska, B.; Wóycicki, W. Heat Capacities of Liquids in the Temperature Interval Between 90 and $300 \mathrm{~K}$ and at Atmospheric Pressure. III Heat Capacities and Excess heat Capacities of (nHexan-1-ol + n-Hexane). J . Chem. Thermodyn. 1984, 16, 609613.

(11) Parks, G. S.; Kennedy, W. D.; Gates, R. R.; Mosley, J . R.; Moore G. E.; Renquist, M. L. Thermal Data on Organic Compounds. XXVI. Some Heat Capacity, Entropy and Free Energy Data for Seven Compounds Containing Oxygen. J . Am. Chem. Soc. 1956, 78, 56-59.

(12) Cline, J. K.; Andrews, D. H. Thermal Energy Studies. III. The Octanols. J. Am. Chem. Soc. 1931, 53, 3668-3673.

(13) Zábranský, M.; Bureš, M.; Růžička, V., J r. Types of Curves for the Temperature Dependence of the Heat Capacity of Pure Liquids. Thermochim. Acta 1993, 215, 25-45.

Received for review April 29, 2003. Accepted J une 22, 2003. This work was supported by the Ministry of Education of the Czech Republic under Grant Number CB MSM 223400008. 